\title{
Zooplankton sampling strategies for environmental studies
}

\author{
Marlene S. Evans \& Daniel W. Sell \\ Great Lakes Research Division, University of Michigan, Ann Arbor, MI 48109, U.S.A.
}

Keywords: variance, sampling, zooplankton, environmental studies, strategy

\begin{abstract}
This study characterizes sources of variation in total zooplankton abundance estimates at seven stations within the 5-10 m depth contour of southeastern Lake Michigan which were sampled monthly, April through October, for the 1975 to 1979 period. Month, year, and station were statistically significant factors affecting abundance estimates as were all interactions. Month was the largest source of variance either as a main effect or interaction. Smallest coefficients of variation were associated with subsampling (mean $6.1 \%$ ) and replicate sampling (mean $15.1 \%$ ). The between-station coefficient of variation averaged $39.0 \%$ and tended to be highest during the summer. For a given station and month, the between-year coefficient of variation averaged $73.4 \%$ while the between-month coefficient of variation for a single station in a given year averaged $95.1 \%$. A table shows the estimated number of replications necessary to detect a true difference in two population means as a function of coefficient of variation. Environmental studies designed to detect spatial alterations should conduct such analyses on a cruise-by-cruise basis. Cruises should consist of a large number of stations and be conducted at least once during each season. Studies designed to detect temporal alterations require more frequent sampling because of the greater variability associated with temporal data sets. Because spatial variability adds little to the overall variability of such data sets, only a few representative stations need be sampled during each cruise.
\end{abstract}

\section{Introduction}

It is well known that zooplankton are variable along temporal and spatial gradients; however, this variability seldom has been quantified statistically. Variability affects the precision of population estimates and raises two basic concerns for environmental studies attempting to detect changes in populations as a result of some perturbation. First, are differences in population means over time or space within the inherent variability of the system or are such differences indicative of some environmental perturbation? Second, how sensitive is a study design in detecting shifts in the population mean?

Our long-term (1971-1982) monitoring study of zooplankton populations in southeastern Lake
Michigan (Evans et al. 1978; Evans et al. 1982) provides an excellent data base for evaluating annual, seasonal, and spatial variability in zooplankton populations. Specific questions we have investigated regarding zooplankton abundance estimates are: 1) What is the contribution of time, space, and time-space interaction to the variance in zooplankton abundance estimates? 2) Given particular sources of variation, how sensitive are various sampling programs in detecting shifts in the population mean? 3) How might a sampling program be improved to increase its sensitivity to detect spatial and temporal alterations in zooplankton populations? 
Although the results are specific to the sources of variability identified in our study, they exemplify an approach which can be used to obtain more precise abundance estimates. Generalities determined by our study have broad application to a variety of population studies, although details will vary with the system and methods employed.

\section{Materials and methods}

Trends of spatial and temporal variability discussed in this paper are derived from samples at stations in the inshore region ( 5 to $10 \mathrm{~m}$ depth contour; Evans et al. 1980) of a wider survey area located in southeastern Lake Michigan. The seven inshore station subset was chosen because the stations (Fig. 1) represent the lake region most extensively sampled over the course of the study. These seven stations were sampled once a month from

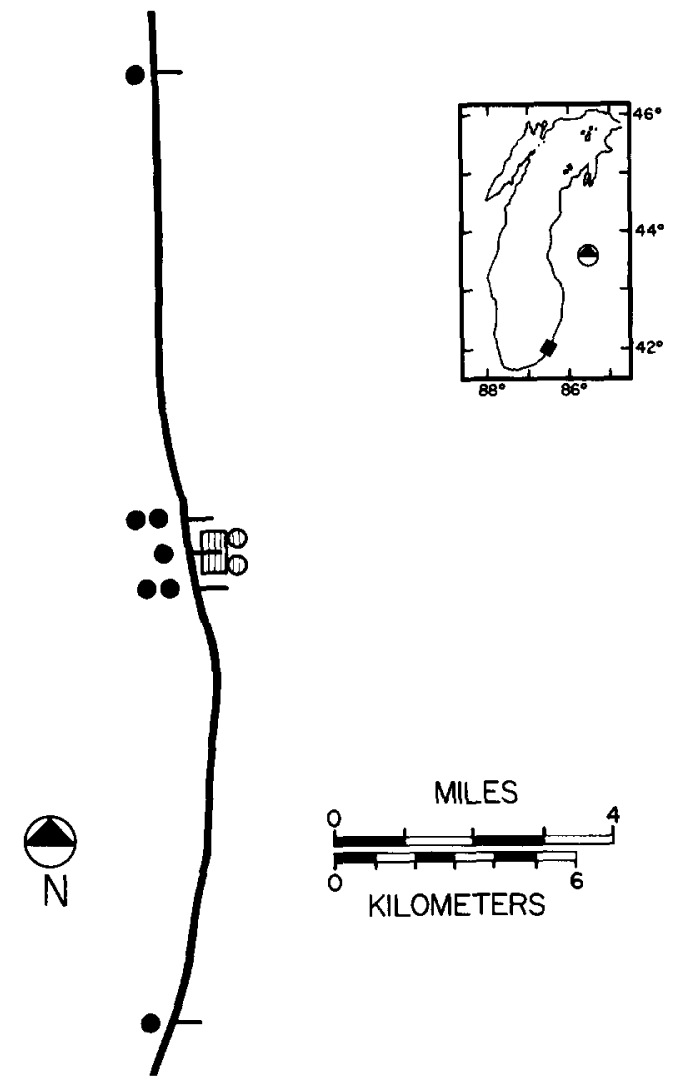

Fig. I. The locations of the seven stations sampled monthly, April through October, for the 1975 to 1979 period. The inset shows the location of the survey grid relative to Lake Michigan.
April to October, 1975 to 1979. A detailed description of the history of the monitoring study is provided by Evans et al. 1982).

Zooplankton were collected at each station with a $50-\mathrm{cm}, 156-\mu \mathrm{m}$ mesh net equipped with a calibrated flowmeter and hauled from approximately $1 \mathrm{~m}$ off the lake bottom to the surface. Two replicate samples were collected at each station. The outside of the net was washed down and zooplankton were preserved with a sugar-formalin solution (Haney \& Hall 1973).

In the laboratory, each subsample was subdivided in a Folsom plankton splitter to give two subsamples of 350-500 animals each. A third subsample containing 700-1000 animals was examined for rare taxa whose total count in the first two subsamples was less than forty. Methods for identifying copepods and cladocerans in the samples are provided in Evans et al. (1982). Sample densities were calculated by averaging the densities determined from the subsamples. Station densities (numbers $/ \mathrm{m}^{3}$ ) similarly were calculated by averaging the sample density estimates.

Analysis of variance (ANOVA) was used to investigate the effects of month and season on zooplankton abundance (numbers $/ \mathrm{m}^{3}$ ). A two-way (month $\times$ station) ANOVA was performed on sample data by year for each of the five years considered in this paper. A fixed-effects model was used (Table 1) with month and station as fixed factors. Variances due to main effects and the interaction were calculated by using the appropriate formula (Table 1). A fixed-effects model was used because the same geographic locations (stations) were sampled each month and cruises were conducted during the same period of each month throughout the study.

A second set of analyses investigated the effect of year and station on zooplankton abundance estimates. The two-way ANOVAs (year $\times$ station) individually used April (spring), July (summer), and October (autumn) sample data for the seven stations over the 1975 to 1979 period. A three-way ANOVA (month $X$ year $\times$ station) was performed on the entire sample data set ( 7 months $\times 7$ stations $\times 5$ years $\times 2$ replicates) using a fixed-effects model. Data were log-transformed to better meet the assumptions of normality: the statistical design was complete with no missing cells. Analyses were performed using the BIOMD:8V statistical program as 
Table l. Anova table for two factor and three factor analysis of variance for fixed effects model.

\begin{tabular}{|c|c|c|c|c|c|}
\hline Source & Sum of squares & Degrees of freedom & Mean square & Expected mean square & F - Statistic \\
\hline \multicolumn{6}{|c|}{ 2-factor analysis } \\
\hline Month & $\mathrm{SS}_{\mathrm{m}}$ & $1-1$ & $\mathrm{MS}_{\mathrm{m}}$ & $\sigma^{2}+\mathrm{JN}_{\sigma m^{2}}$ & $F(I-1), I J(K-1)$ \\
\hline Station & $\mathrm{SS}_{\mathrm{s}}$ & $J-1$ & $\mathrm{MS}_{\mathrm{s}}$ & $\sigma^{2}+\mathrm{IN}_{\sigma \mathrm{s}} \mathrm{s}^{2}$ & $\mathbf{F}(\mathrm{I}-\mathbf{1}), \mathbf{I J}(\mathrm{K}-1)$ \\
\hline $\mathrm{M} \times \mathrm{S}$ & $\mathrm{SS}_{\mathrm{ms}}$ & $(1-1)(J-1)$ & $\mathrm{MS}_{\mathrm{ms}}$ & $\sigma^{2}+\mathrm{N}_{o m s^{2}}$ & $\mathrm{~F}(\mathrm{I}-1)(\mathrm{J}-1), \mathbf{I J}(\mathrm{K}-1)$ \\
\hline Error & $\mathrm{SS}_{\mathrm{e}}$ & $\mathbf{I J}(\mathrm{N}-1)$ & $\mathrm{MS}_{\mathrm{e}}$ & $\sigma^{2}$ & - \\
\hline Total & $\mathrm{SS}_{\mathrm{t}}$ & IJK-1 & - & - & - \\
\hline \multicolumn{6}{|c|}{ 3-factor analysis } \\
\hline Month & $\mathrm{SS}_{\mathrm{n}}$ & $1-1$ & $\mathrm{MS}_{\mathrm{m}}$ & $\sigma^{2}+J K N_{\sigma^{2} \mathbf{m}}$ & $\mathrm{F}(\mathrm{I}-1), \mathrm{IJK}(\mathrm{N}-1)$ \\
\hline Station & $\mathrm{SS}_{\mathrm{s}}$ & $\mathrm{J}-1$ & $\mathrm{MS}_{\mathrm{s}}$ & $\sigma^{2}+I K N_{\sigma^{2} \mathrm{~s}}^{\sigma_{1}}$ & $\mathrm{~F}(\mathrm{~J}-1), \mathrm{IJK}(\mathrm{N}-1)$ \\
\hline Year & $\mathrm{SS}_{\mathrm{y}}$ & $\mathrm{K}-1$ & $\mathrm{MS}_{\mathrm{y}}$ & $\sigma^{2}+I J N_{\sigma^{2} y}$ & $\mathbf{F}(\mathrm{K}-1), \mathbf{I J K}(\mathrm{N}-1)$ \\
\hline $\mathrm{M} \times \mathrm{S}$ & $\mathrm{SS}_{\mathrm{ms}}$ & $(I-1)(J-1)$ & $\mathrm{MS}_{\mathrm{ms}}$ & $\sigma^{2}+K_{\sigma^{2} \mathrm{~ms}}$ & $\mathrm{~F}(\mathrm{I}-1)(\mathrm{J}-1)$, IJK$(\mathrm{N}-1)$ \\
\hline $\mathrm{Y} \times \mathrm{M}$ & $\mathrm{SS}_{\mathrm{ym}}$ & $(\mathrm{I}-1)(\mathrm{K}-\mathrm{I})$ & $\mathrm{MS}_{\mathrm{ym}}$ & $\sigma^{2}+\mathrm{JN}_{\sigma^{2} \mathrm{ym}}$ & $\mathrm{F}(\mathrm{I}-1)(\mathrm{K}-1), \mathbf{I J K}(\mathrm{N}-1)$ \\
\hline $\mathrm{Y} \times \mathrm{S}$ & $\mathrm{SS}_{\mathrm{ys}}^{\mathrm{gin}}$ & $(\mathrm{J}-1)(\mathrm{K}-1)$ & $\mathrm{MS}_{\mathrm{ys}}$ & $\sigma^{2}+\mathbf{I N}_{\sigma^{2} \mathrm{ys}}$ & $\mathrm{F}(\mathrm{J}-1)(\mathrm{K}-1), 1 \mathrm{JK}(\mathrm{N}-1)$ \\
\hline $\mathrm{Y} \times \mathbf{M} \times \mathbf{S}$ & $\mathrm{SS}_{\mathrm{yms}}$ & $(\mathrm{I}-1)(\mathrm{J}-1)(\mathrm{K}-1)$ & $\mathrm{MS}_{\mathrm{yms}}$ & $\sigma^{2}+\mathrm{N}_{\sigma^{2} \mathrm{yms}}$ & $\mathrm{F}(\mathrm{I}-1)(\mathrm{J}-1)(\mathrm{K}-1), \mathrm{IJK}(\mathrm{N}-1)$ \\
\hline Error & $\mathrm{SS}_{\mathrm{e}}$ & $1 J K(N-1)$ & $\mathrm{MS}_{\mathrm{e}}$ & $\sigma^{2}$ & - \\
\hline Total & $\mathrm{SS}_{\mathrm{t}}$ & IJKN-I & - & - & - \\
\hline
\end{tabular}

1 = Number of levels of month $(7$, fixed)

$\mathbf{J}=$ Number of levels of station ( 7, fixed)

$\mathrm{K}=$ Number of levels of year $(5$, fixed)

$N=$ Number of replicates $(2$, random)

implemented on the University of Michigan Computer System. Output from this program included the appropriate formula for the expected mean square.

As a first step in investigating the sensitivity of a sampling program to detect a true difference between population means, coefficients of variation were calculated (raw data) for a number of data sets. This allowed quantification of sources of variability in estimating population means at a station, over a region of the survey grid, and over time. The following coefficients of variation $(\mathrm{CV})$ were calculated: 1) the $\mathrm{CV}$ between subsamples for each of the 490 paired subsamples ( 7 stations $\times 7$ months $\times 2$ samples $\times 5$ years); 2) the $\mathrm{CV}$ between replicate samples for the 245 paired replicates ( 7 stations $\times 7$ months $\times 5$ years) data set; 3 ) the CV between the seven stations for each of the 35 cruise ( 7 months $X$ 5 years) data sets; 4) the CV between the seven months for each of the seven stations in each of the five years studied (a total of 35 values); 5 ) the $\mathrm{CV}$ between years by station and by month. This represented a total of 49 calculations for each of the seven stations sampled in each of the seven months. 6) mean CVs were calculated by month and by year for the above statistics to investigate seasonal and year-to-year differences in variability.

Coefficients of variation involving station, month, or year were calculated using station data. As stated earlier, the abundance estimate for each station was based on the mean of two replicate samples, each of which based on the abundance mean of two subsamples. Thus, to calculate the coefficient of variation between stations in April 1979, we used the seven station abundance estimates. This coefficient of variation included variation due to between-station variability but also included variance due to subsampling and replicate sampling. By basing the between station coefficient of variation on station means rather than estimates derived from a single sample from each station or a single subsample from a single sample, we minimized the subsampling and replicate sampling variance. The actual magnitude of variance due to subsampling and replicate sampling is shown later in the text. However, for most studies, such variance is a relatively small source of variance in comparison to variance due to spatial and temporal factors.

By knowing the coefficient of variation (or var- 
iance) associated with a population mean estimate, it is possible to calculate the approximate number of replicates necessary to statistically detect a given true difference in population means with a specified level of certainty. The following formula presented by Sokal and Rohlf (1969) was used:

$\mathrm{n}>=2(\sigma / \delta)^{2}\left\{\mathrm{t}_{\alpha[\nu]}+\mathrm{t}_{2(1-\mathrm{P})[\nu]}\right\}^{2}$

where

$\mathrm{n}=$ number of replications

$\sigma=$ true standard deviation

$\delta=$ the smallest true detectable difference. It is not necessary to know the absolute values of $\sigma$ and $\delta$. Only the ratio is needed; for example, the ratio between the coefficient of variation and a percent difference in the means.

$v=$ degrees of freedom of the sample standard deviation (MS within) with ' $a$ ' groups and ' $n$ ' replicates where $v=\mathrm{a}(\mathrm{n}-1)$.

$\alpha=$ significance level

$\mathbf{P}=$ desired probability that a difference will be found to be significant if it is a small as $\delta$.

$\mathrm{t}_{\alpha[v]}$ and $\mathrm{t}_{2(1-P)[v]}$ are values from a two-tailed t-test with $v$ degrees of freedom and corresponding to probabilities of $\alpha$ and 2(1-P) respectively.

A table was constructed by selecting coefficients of variation (ranging from $5 \%$ to $200 \%$ ) and percent differences in means $(6$ levels ranging from $10 \%$ to $200 \%$ ) between two populations. A significance level of 0.05 and a desired probability $(P)$ of 0.80 were selected. Such two-population comparisons include 'before' versus 'after' populations, experimental versus control populations, station A versus station $B$, etc. After the initial conditions were set, an iterative procedure was employed to solve for ' $n$ ', the number of replicates required for each population. By knowing the coefficient of variation associated with a data set and the number of replications, the table can be used to estimate the sensitivity of a study to detect differences in population means.

\section{Results}

Month and station were statistically significant $(\alpha=0.05)$ factors affecting zooplankton abundance estimates for the April through October period of each year (Table 2). The interaction between month and station also was significant indicating that main effects were not additive. Most of the ex-
Table 2. Analysis of variance of log-transformed zooplankton abundance data by year at 7 stations and 7 months with 2 replicates per station.

\begin{tabular}{|c|c|c|c|}
\hline Source & F-Statistic & Variance & $\begin{array}{l}\% \text { of the } \\
\text { variance }\end{array}$ \\
\hline \multicolumn{4}{|l|}{1975} \\
\hline M & $189.8147^{*}$ & 0.1449 & 71.31 \\
\hline $\mathbf{S}$ & $18.6226^{*}$ & 0.0135 & 6.64 \\
\hline MS & $6.0788^{*}$ & 0.0273 & 13.44 \\
\hline Error & & 0.0175 & 8.61 \\
\hline \multicolumn{4}{|l|}{1976} \\
\hline $\mathbf{M}$ & $415.1778^{*}$ & 0.2216 & 72.39 \\
\hline $\mathbf{S}$ & $8.4781^{*}$ & 0.0040 & 1.31 \\
\hline MS & $10.7477^{*}$ & 0.0730 & 23.86 \\
\hline Error & & 0.0075 & 2.45 \\
\hline \multicolumn{4}{|l|}{1977} \\
\hline M & $155.6044^{*}$ & 0.0987 & 56.53 \\
\hline $\mathbf{S}$ & $40.8967^{*}$ & 0.0255 & 14.60 \\
\hline MS & $10.2903^{*}$ & 0.0415 & 23.77 \\
\hline Error & & 0.0089 & 5.10 \\
\hline \multicolumn{4}{|l|}{1978} \\
\hline M & $476.9955^{*}$ & 0.2354 & 78.70 \\
\hline S & $19.3101^{*}$ & 0.0091 & 3.04 \\
\hline MS & $14.7557^{*}$ & 0.0477 & 15.95 \\
\hline Error & & 0.0069 & 2.31 \\
\hline \multicolumn{4}{|l|}{1979} \\
\hline M & $235.9388^{*}$ & 0.1272 & 81.42 \\
\hline $\mathbf{S}$ & $12.4697^{*}$ & 0.0062 & 3.97 \\
\hline MS & $5.0248^{*}$ & 0.0152 & 9.74 \\
\hline Error & & 0.0076 & 4.87 \\
\hline
\end{tabular}

* = Significant at the 0.05 significance level.

plained variance was due to month $(56.5 \%$ to $81.4 \%$ ) while station accounted for a relatively small percent ( $1.3 \%$ to $14.6 \%)$ of the variance. Station-month interaction accounted for an additional $9.7 \%$ to $23.9 \%$ of the variance. Variance due to station was highest in 1977 while variance due to month was largest in the 1976 and 1978 ANOVA's.

Analysis of variance was performed for April (spring), July (summer), and October (autumn) 1975 to 1979 data sets to remove effects due to month (Table 3) and to investigate the main factor year. Year and station were significant main effects $(\alpha=0.05)$ as was the interaction term. Variances due to station and year were largest in July. Station accounted for a relatively small percentage of the explained variance $(5.3 \%$ to $8.0 \%)$ while year accounted for a relatively large amount $(54.4 \%$ to $74.6 \%)$ of the variance. Similar analyses of the 5-year, 7-month, 7-station data set (Table 4) indi- 
Table 3. Analysis of variance of log-transformed zooplankton abundance data by year and station.

\begin{tabular}{lccc}
\hline Source & F-Statistic & Variance & $\begin{array}{r}\% \text { of the } \\
\text { variance }\end{array}$ \\
\hline April & & & \\
Y & $133.88^{*}$ & 0.0820 & 74.55 \\
S & $7.67^{*}$ & 0.0058 & 5.27 \\
YS & $4.15^{*}$ & 0.0136 & 12.37 \\
Error & & 0.0086 & 7.82 \\
July & & & \\
Y & $173.99^{*}$ & 0.1654 & 65.82 \\
S & $16.02^{*}$ & 0.0202 & 8.04 \\
YS & $8.79^{*}$ & 0.0523 & 20.81 \\
Error & & 0.0134 & 5.33 \\
October & & & \\
Y & $170.39^{*}$ & 0.0412 & 54.35 \\
S & $17.26^{*}$ & 0.0055 & 7.26 \\
YS & $16.12^{*}$ & 0.0257 & 33.91 \\
Error & & 0.0034 & 4.49 \\
\hline
\end{tabular}

* = Significant at the 0.05 significance level.

cated that all main effects and interactions were statistically significant. Most of the explained variance was due to month or to interactions involving month.

The coefficient of variation between subsamples ranged from less than $1 \%$ to $23.6 \%$ and averaged $6.1 \%$. The mean coefficient of variation for subsamples did not exhibit a strong seasonal trend (Fig. 2) nor did it vary substantially between years (Fig. 3).

The coefficient of variation between replicate samples at one station ranged from $0.0 \%$ to $74.4 \%$ and averaged $15.1 \%$. The mean coefficient of varia-

Table 4. Analysis of variance of log-transformed zooplankton abundance data by year, month, and station. Seven stations were sampled for five years (1975-1979) between April and October.

\begin{tabular}{lrrr}
\hline Source & F-Statistic & Variance & $\begin{array}{r}\text { \% of the } \\
\text { variance }\end{array}$ \\
\hline Y & $122.003^{*}$ & 0.0122 & 4.35 \\
M & $731.812^{*}$ & 0.0870 & 33.76 \\
S & $59.271^{*}$ & 0.0069 & 2.68 \\
YM & $165.888^{*}$ & 0.0982 & 38.11 \\
YS & $10.898^{*}$ & 0.0064 & 2.48 \\
MS & $12.185^{*}$ & 0.0093 & 3.61 \\
YMS & $8.295^{*}$ & 0.0304 & 11.80 \\
Error & & 0.0083 & 3.22 \\
\hline
\end{tabular}

* = Significant at the 0.05 significance level.

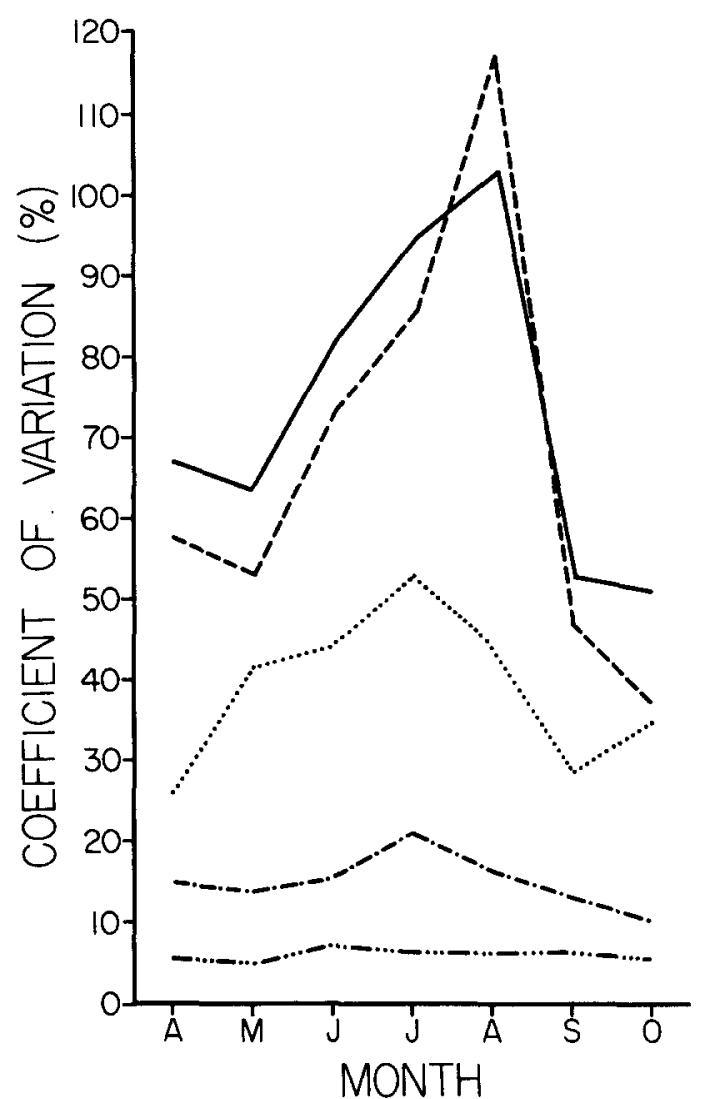

Fig. 2. The mean coefficient of variation (\%) by month for (a) -... subsamples, (b) -.-. replicate net hauls, (c) .... stations by cruise, (d) - - - individual stations between years, (e) - - cruise mean ( 7 stations) between years.

tion between replicate samples was lower in spring and autumn than in summer (Fig. 2).

The coefficient of variation between stations for a given cruise ranged from $12.2 \%$ to $78.0 \%$ and averaged $39.0 \%$ for the 35 cruises. It was lower in spring and autumn than in summer (Fig. 2) and followed a similar seasonal pattern as the coefficient of variation between replicate hauls. Similarly, zooplankton exhibited greater between-station variability in some years (1977) than others (Fig. 3).

For a given station and a given month, the mean coefficient of variation between years ranged from $29.8 \%$ to $161.2 \%$ and averaged $73.4 \%$. It was lowest (Fig. 2) in the spring and autumn (51\% to $67 \%)$ and highest in the summer $(94.6 \%$ to $103 \%)$. The seasonal pattern differed from the coefficients of variation for replicate sampling and for station. A second set of coefficients of variation was calculated based on a 7-station mean for each cruise. With the 


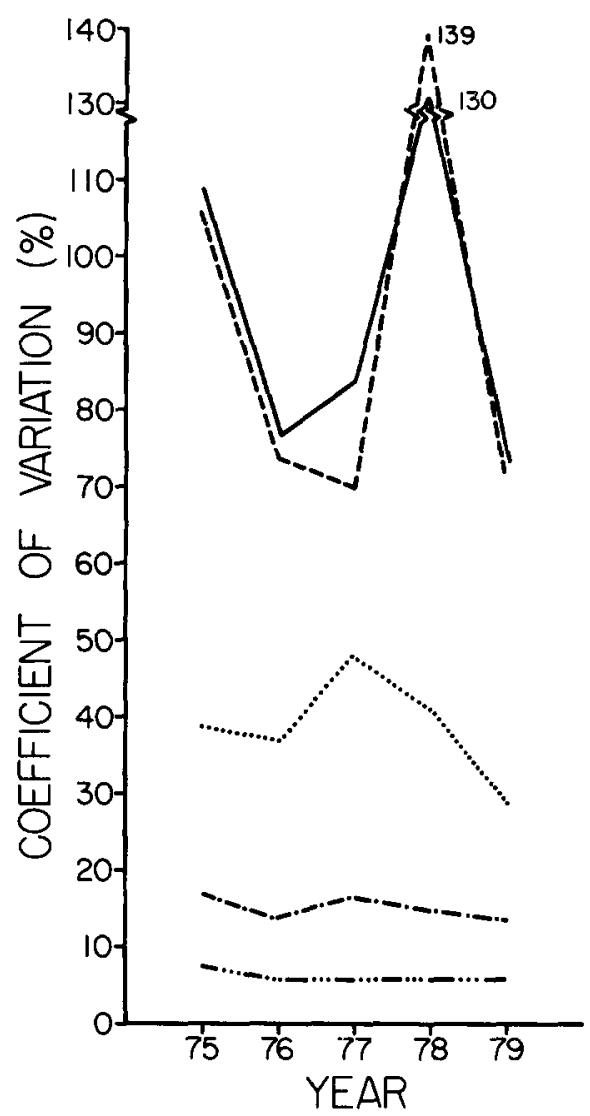

Fig. 3. The mean coefficient of variation (\%) by year for (a) -...-subsamples, (b) - -.. replicate hauls, (c) $\ldots$... individual stations, (d) -- - between-months by individual station, (e) the between-months for cruise means ( 7 stations).

exception of August (Fig. 2), the between-year coefficients of variation (mean $67.5 \%$ ) were lower than similar coefficients of variation based on individual stations.

The coefficient of variation associated with time factors was highest when coefficients were based on population means over several months. For a given station and year, the coefficient of variation over the 7-month cruise season (Fig. 3) ranged from $43.8 \%$ to $199.5 \%$ and averaged $95.1 \%$. This mean coefficient of variation was reduced only to $92.3 \%$. when calculations were based on a 7-station mean for each cruise. Zooplankton were more seasonal in abundance in some years than others with the greatest seasonality occurring in 1975 and 1978.

Table 5 shows the relationship between the coefficient of variation and the number of replicates required to detect a $10 \%, 25 \%, 50 \%$, or $100 \%$ differ-
Table 5. Number of replications necessary to be $80 \%$ certain of detecting ( $\alpha=.05)$ a true difference $(\%)$ between the means of two populations as a function of the coefficient of variation (\%) of the populations.

\begin{tabular}{|c|c|c|c|c|c|c|}
\hline \multirow{2}{*}{$\begin{array}{l}\text { Coefficient } \\
\text { of } \\
\text { variation } \\
(\%)\end{array}$} & \multicolumn{6}{|c|}{ True difference in population means } \\
\hline & $10 \%$ & $25 \%$ & $50 \%$ & $100 \%$ & $150 \%$ & $200 \%$ \\
\hline 5 & 5 & 2 & 2 & 2 & 2 & 2 \\
\hline 10 & 17 & 4 & 2 & 2 & 2 & 2 \\
\hline 20 & 64 & 11 & 4 & 2 & 2 & 2 \\
\hline 30 & 144 & 24 & 7 & $2-4$ & 2 & 2 \\
\hline 40 & 255 & 41 & 11 & 4 & $2-4$ & 2 \\
\hline 50 & 399 & 64 & 17 & 5 & $2-4$ & $2-4$ \\
\hline 60 & 575 & 92 & 24 & 7 & 4 & $2 \cdot 4$ \\
\hline 70 & 782 & 125 & 32 & 9 & $4-5$ & $2-4$ \\
\hline 80 & 1022 & 163 & 41 & 11 & $5-6$ & 4 \\
\hline 90 & 1293 & 207 & 52 & 14 & 7 & $4-5$ \\
\hline 100 & 1596 & 255 & 64 & 17 & 8 & 5 \\
\hline 125 & 2494 & 399 & 100 & 26 & 12 & 7 \\
\hline 150 & 3591 & 575 & 144 & 36 & 17 & 10 \\
\hline 175 & 4888 & 782 & 196 & 49 & 22 & 13 \\
\hline 200 & 6385 & 1022 & 255 & 64 & 29 & 17 \\
\hline
\end{tabular}

ence in the means of two populations at the 0.05 significance level and with a certainty of $80 \%$. For low coefficients of variation $(<40 \%)$, a relatively small number of replicates are required from each population to detect true differences in means. However, as the coefficient of variation increases, larger numbers of replicates are required.

\section{Discussion}

Many factors affect the precision and accuracy of zooplankton population estimates. Quantification of sources of variability allows a better understanding of the statistical resolution of a study and suggests improvements in study design (Cassie 1971; Green 1979).

The smallest source of variance, averaging $6.1 \%$, was due to subsampling procedures. While the coefficient of variation could be reduced by increasing the number of subsamples examined, this would result in only a small increase (and at great expense) in the precision of population estimates (Sell \& Evans 1982).

The next largest coefficient of variation, averaging $15.1 \%$, was associated with replicate sampling at a station. Sell \& Evans (1982) also showed that 
replicate sampling at a single station (June 1980) accounted for a larger percentage of the total variance than variance due to subsampling. Replicate sampling is useful because it allows investigations of interactions in multifactor ANOVA designs. Without such replication, the highest order interaction term is used as an estimate of the mean square error necessary to compute the F-statistic (Neter \& Wasserman 1974). Consequently, the highest-order interaction term cannot be fully investigated. Our study has determined that this interaction was significant and was a major component of variance. This has two statistical implications. First, erroneous conclusions can be drawn from a study by making the invalid assumption that the highestorder interaction term is statistically nonsignificant. Secondly, since the highest-order interaction mean square was a major source of variance (Tables 2,3 , and 4), using this term as an estimate of the mean square error can result in an over-estimate of the relative magnitude of the error term. This can result in a reduction in the calculated F-statistic for the main effects and the lower-order interaction terms with a subsequent reduction of the power of the test. Since station was a relatively small source of variance in the month $X$ station and the month $X$ station $X$ year ANOVA's, using this approach could result in a researcher incorrectly concluding that station was not a statistically significant factor (as a main effect or interaction; Tables 2, 3, and 4).

The coefficient of variation for replicate sampling (mean 15.1\%) and for between-stations (mean $39.0 \%$ ) varied seasonally and tended to be highest in summer. This suggests that zooplankton are more patchily distributed in some months than others both on scales of meters (replicate samples) and hundreds of meters (between stations). Differential patchiness may be related to biological and physical factors. The spring and autumn zooplankton community is dominated by copepods having generation times of several weeks. Conversely, the summer community is dominated by cladocerans (Evans et al. 1980) having generation times of days (Allan 1976). High reproductive rates may allow summer zooplankton to respond more rapidly to small changes in environmental conditions. In addition, during summer, the water column is stable as high temperatures and thermal gradients increase thermal resistance to mixing (Wetzel 1975). Thus, zooplankton are less readily mixed by physi- cal processes during the warmer months of the year contributing to greater patchiness. During summer, when zooplankton are vertically stratified in relation to thermal gradients (Wells 1960), localized upwellings also may result in large between-station variance.

Seasonality accounted for the largest variance both as the main effect month and the month $X$ year interaction (Table 4). The month $X$ year interaction is due to differences in seasonal events across years. For example, in one year, a July cruise may be conducted during an upwelling, but not in the subsequent year. In one mid-April cruise, the spring zooplankton pulse may be well-developed while, one year later, zooplankton reproduction may be delayed due to lower water temperatures. Differences in seasonality between years affect population estimates for a given month and year. A single cruise conducted in a month does not provide a precise estimate of overall population levels for that month, resulting in high coefficients of variation (average $73.4 \%$ ) between years. Coefficients of variation between years based on the mean of several population estimates over a year are lower (average $20.1 \%$ ) because such estimates include seasonal replication.

Researchers in environmental perturbation studies have two basic concerns. First, are populations in the vicinity of a perturbation (thermal effluent, nutrient, or other discharge) different from populations in control regions? Second, does the perturbation result in temporal shifts in population characteristics?

In order to characterize the spatial distribution of zooplankton before and during a perturbation, spatially intensive (many stations sampled over the survey area) cruises should be conducted at least once in each season. Cruises conducted at the beginning of the study will allow the researcher to characterize the between-station variability of the area, stratify the survey grid into regions with similar population characteristics, and redesign the survey grid to include a sufficient number of stations to detect the level of change.

Since zooplankton abundances vary significantly from year to year, 'before' type studies should be conducted over at least two years to quantify this variability. Cruises designed to provide detailed information on the temporal distribution of zooplankton should be conducted at least monthly and 
preferably weekly or biweekly. However, because the spatial component of variance is a relatively small source of total variance (Table 3,4 ), it is not necessary to intensively sample the entire study area during each cruises. A few representative stations should be sufficient to investigate temporal trends.

After the perturbation begins, the researcher must evaluate its effects on the spatial and temporal characteristics of the zooplankton population. Each type of evaluation requires a distinct statistical approach.

Analyses investigating spatial alterations on zooplankton populations should do so on a cruise by cruise basis: temporal factors account for a large amount of variability in zooplankton abundance estimates and can confound the immediate detection of spatial trends. While at the beginning of the perturbation, spatially-intensive cruises should be conducted at least once each season, the frequency of such cruises later can be reduced if spatial effects are not detected or are sufficiently quantified.

In order to evaluate temporal alterations in populations, 'before' and 'after' type statistical comparisons can be performed in two basic ways: by month or by year. Month comparisons across 'before' and 'after' data blocks are useful to investigate specific effects related to seasonality in zooplankton composition and sensitivity to stress. A disadvantage to this approach can be the high coefficient of variation (Table 5) associated with such data sets $(73.1 \%$ in our study). 'Before' and 'after' comparisons based on zooplankton mean abundances for each year lose information on specific seasonal effects. However, the coefficient of variation between years can be low (mean $20.1 \%$ in our study) with the result that the statistical sensitivity of the study is improved (Table 5).

The results reported here are specific to a subset of our data and vary as a function of the data base considered. For example, the coefficient of variation between subsamples is higher at the species level because of the smaller number of organisms enumerated in species counts than for total zooplankton. Furthermore, the significance of month, station, and year as factors affecting abundance estimates varies with the taxon (Lewis 1978; Evans, unpubl. data). The between-station coefficient of variability increases as the data base considered in this paper is expanded to include stations in different geographic regions of the lake. The higher level (station, month, year) coefficients of variation are affected by the number of subsamples enumerated, the number of organisms identified in each subsample, and the number of replicates collected at each station. This is because the higher level coefficients of variation include lower level variance due to subsampling and replicate sampling. Consequently, if these lower level sources of variation are not minimized, the higher level coefficients of variation will increase. Sell \& Evans (1982) discuss optimal allocation of effort for subsampling and replicate sampling based on considerations of their relative magnitude of variance and collection costs.

Our study has provided specific information on sources of variability in zooplankton abundances estimates, sensitivity of study design to detect differences in populations means, and suggests areas in which detection limits of the study can most realistically be improved. For example, in our study, the average between-station coefficient of variation is nearly $40 \%$. With seven stations in the vicinity of the power plant and seven stations in the control region, shifts in population means of 50 to $100 \%$ can be detected. The true loss of zooplankton in the vicinity of the plant is estimated at less than 10\% (Evans et al. 1982). An extremely large number of stations would need to be sampled in both control and plume regions to detect this small loss.

The results of our study can be extended to other studies. From Table 5, it is evident that the smaller the data base, the more cautious the researcher must be interpreting the ecological significance of differences in population means. With very limited data sets, only very large differences $(>150 \%$ or more) should be given much ecological significance. Classic studies purporting changes in zooplankton populations as a result of fish predation have been based on such large-magnitude changes (Brooks and Dodson 1965; Wells 1970), although these data were not subjected to statistical analysis.

Monitoring and surveillance studies often are confounded by variability with possible environmental effects below the detection limit of the study. Our results indicate that researchers conducting such investigations should be cognizant of the statistical sensitivity of their study design. Such knowledge will allow the researcher to redesign a study to most efficiently (and frugally) quantify the effects of a perturbation. The results of our study also indicate that, with poor planning (low numbers 
of animals enumerated in subsamples, lack of replication, too few stations sampled in the affected region, infrequent sampling, etc.), a study will be designed that will fail to detect any but the most gross alterations in populations. While such studies may conclude that no pertubation effects were detected, is important to recognize that study design and not the absence of an effect was the primary factor responsible for such a conclusion.

\section{Acknowledgements}

This research was sponsored by the Indiana \& Michigan Electric Company. Dr. John Ayers provided support and encouragement throughout the study. Special thanks are extended to reviewers Drs. William Chang, Russell Moll, and Eugene Stoermer. Dr. Gary Fowler provided valuable comments on an earlier version of the manuscript. Francis Figg prepared the figures. Contribution number 349, Great Lakes Research Division.

\section{References}

Allan, J. D., 1976. Life history patterns in zooplankton. Am. Nat. 110: 165-180.

Brooks, J. L. \& Dodson, S. I., 1965. Predation, body size, and composition. Science 150: $28-35$.

Cassie. J. M., 1971. Sampling design and statistics. In: Edmondson, W. T. \& Winberg, G. C. (Eds.) A Manual on Methods for the Assessment of Secondary Productivity in Fresh Waters. IBP Handbook no. 17. Blackwell Scient. Publ., Oxford: 174. 209.

Elliot, J. M., 1977. Some Methods for the Statistical Analysis of Samples of Benthic Invertebrates. Freshwat. biol. Ass. Publs. 25. 160 pp.
Evans, M.S., 1981. Distribution of zooplankton populations within and adjacent to a thermal plume. Can. J. Fish. Aquat. Sci. 38: 441-448.

Evans, M. S., Wurster, T. E. \& Hawkins, B. E., 1978. The 1975 and 1976 Operational Zooplankton Investigations Relative to the Donald C. Cook Nuclear Power Plant, with Tests for Plant Effects (1971-1976). Univ. Mich. Great Lakes Res. Div. Spec. Rept. 64. 166 pp.

Evans, M. S., Hawkins, B. E. \& Sell, D. W., 1980. Seasonal features of zooplankton assemblages in the nearshore region of southeastern Lake Michigan. J. Great Lakes Res. 6: 275-289.

Evans, M. S., Sell, D. W. \& Page, D. I., 1982. Zooplankton studies in 1977 and 1978 at the Donald C. Cook Nuclear Power Plant: Comparisons of Preoperational (1971-1974) and Operational (1975-1979) Population Characteristics. Univ. Mich. Great Lakes Res. Div. Spec. Rept. 89. 235 pp.

Green, R. H., 1979. Sampling design and statistical methods for environmental biologists. Wiley-Interscience, N.Y. 257 pp.

Haney, J. F. \& Hall, D. J., 1973. Sugar-coated Daphnia: A preservation technique for Cladocera. Limnol. Oceanogr. 18: $331-333$

Lewis, W. M. Jr., 1978. Comparison of temporal and spatial variation in the zooplankton of a lake by means of variance components. Ecology 59: 666-671.

Neter, J. \& Wasserman, W., 1974. Applied Linear Statistical Models. Richard D. Irwin, Inc., Homewood, III. 842 pp.

Sell, D. W. \& Evans, M. S., 1982. A statistical analysis of subsampling and an evaluation of the Folsom plankton splitter. Hydrobiologia 94: 223-230.

Sokal, R. R. \& Rohlf, F. J., 1969. Biometry. Freeman Press, San Francisco. 776 pp.

Wells, L., 1960. Seasonal abundance and vertical movements of planktonic Crustacea in Lake Michigan. Fishery Bull. Fish. Wildl. Serv. U.S. 60: 343--364.

Wells, L., 1970. Effects of alewife predation on zooplankton populations in Lake Michigan. Limnol. Oceanogr. 15: $556-565$.

Wetzel, R. G., 1975. Limnology. W. B. Saunders Company. Philadelphia. $743 \mathrm{pp}$.

Received 15 June 1982; in revised form 27 September 1982; accepted 27 September 1982. 